\title{
trabahonecessário
}

issn: $1808-799 \mathrm{X}$

ano 3 número $3-2005$

\section{A RESPONSABILIDADE SOCIAL EMPRESARIAL EM QUESTÃO: O PENSAMENTO PEDAGÓGICO DO INSTITUTO ETHOS}

Andréa de Souza Fontes*

Este artigo pretende apresentar uma contribuição para a análise do pensamento pedagógico empresarial a partir das proposições do Instituto Ethos de Empresas e Responsabilidade Social, entidade que vem desenvolvendo suas atividades a partir da nova estratégia chamada responsabilidade social. Na verdade, o que pretendemos encontrar são os "fios condutores e invisíveis" que unem as propostas pedagógicas mais gerais, isto é, hegemônicas, do empresariado às necessidades atuais de manutenção da economia capitalista, pois a correta afirmação de que a burguesia está na constante busca de adequar a educação às necessidades do capitalismo é muito genérica e para especificá-la precisamos atingir a questão em seu centro, estudando as propostas pedagógicas das entidades que buscam construir a hegemonia burguesa.

\section{A questão social: o passado inspira o futuro}

Para compreendermos a proposta contemporânea de responsabilidade social empresarial faz-se necessário apreender a metamorfose da questão social ao longo da história.

Prática antiga da humanidade, a assistência social apresentou ao longo da história diferentes facetas (assumidas ou ocultadas) de acordo com os diversos momentos políticoeconômicos. A assistência pode ser compreendida como conjunto de práticas que tem como objetivo atenuar (ou superar) não só o déficit material, mas principalmente "moral" dos necessitados de uma sociedade (Castel, 1995).

O alvo da assistência social, portanto, é marcado inicialmente pelo atendimento às 
populações isentas ou incapacitadas da obrigação de trabalhar, ameaçadas de afastamento social por serem incapazes de prover suas necessidades por seus próprios meios. A assistência, conseqüência de sociedades estruturadas em classes sociais, é uma intervenção da sociedade sobre si mesma que em todas as épocas teve como objetivo manter a coesão de seus membros e assegurar a paz social.

Na Idade Antiga essa assistência era marcada por laços de pertença às comunidades (ou clãs) que na ausência de instituições utilizavam seus próprios recursos para assistir seus membros mais carentes e assim manter-se equilibrada. Após assumir durante a Idade Média uma face caritativa e cristã e ter institucionalizado práticas do qual se revestiu o Ocidente Cristão, a assistência se metamorfoseia novamente. A Idade Moderna marca o enfraquecimento dos valores católicos contestados pela Reforma Protestante e pela ascensão burguesa, trazendo consigo novas exigências sociais e políticas. Nesse contexto, a questão social passa a ser encarada como um fenômeno social e a assistência ao homem como indivíduo surge de forma secular - não religiosa.

Mais tarde o advento da grande indústria tornaria bem mais complexa a estrutura social afetando profundamente o conjunto das relações sociais, particularmente as condições de reprodução da força de trabalho. Devido à reestruturação econômica oriunda da Revolução Industrial, a Idade Contemporânea traz consigo uma nova formulação da questão social, marcada pelo livre aceso ao trabalho, isto é, pelo trabalho assalariado. Conflitos de classes e crises se acentuam e para amortecer os conflitos é necessário assegurar condições mínimas de vida, isto é, de reprodução da força de trabalho, frente a esses fatores que trazem embutido o risco de fragmentação da sociedade que vê-se obrigada a traçar novas estratégias sociais.

Nesse contexto, surgem as instituições assistenciais e com elas os principais traços de uma política assistencial moderna, que classifica e seleciona seus "beneficiários", que ameniza a miséria, mas que não repensa a partir dela novas condições de existência.

É importante salientar que as sociedades mais complexas são as que mais precisam de um sistema estruturado de práticas visando sua auto-conservação, o que se evidencia nas formas de intervenção e no número de instituições sócio-assistenciais existentes na atual sociedade capitalista. A assistência social estende-se aos indivíduos disponíveis e capazes de trabalhar, mas que não são imediatamente recrutáveis devido às novas exigências de mercado. Em outras palavras, a assistência social pós-revolução industrial visa também o exército de reserva industrial.

Nesse contexto a burguesia fará de tudo, num primeiro momento, para manter o poder público afastado do controle da política econômica e social, mas após um relativo fracasso da "mão invisível" do mercado em controlar esses fatores, juntamente com a ameaça a ordem política e social que a nova questão social, o pauperismo, impunha, novas estratégias são impostas e a intervenção do Estado faz-se necessária para compensar, 
mesmo que por um tempo determinado, as "falhas" desse mercado.

O Estado social, ou seja, aquele que lança mão de políticas assistenciais , foi construído como resposta a essas crises, acreditando-se poder afastar riscos e tecer seguridades. A tarefa da política social (a partir do século XIX) passa a ser de escorar esta nova estrutura de trabalho. O Estado torna-se, então, o principal suporte de proteção e o perigo contido nessa dependência vai se revelar quando o poder público apresentar dificuldades de dar continuidade a essas tarefas, como foi possível nos anos de grande crescimento econômico.

Porém faz-se necessário esclarecer que no decorrer dos anos mesmo sem uma elaboração de políticas públicas sociais, algumas ações sociais foram incorporadas pelos governos nacionais e outras formas irrisórias de assistência sempre estiveram contidas nas práticas dos governos mesmo dos séculos passados, como asilos, hospitais e postos de beneficência, auxílio financeiro a instituições religiosas, entre outras.

Assim, o Estado é mais ou menos obrigado a "fazer o social" institucionalizando serviços de assistência para amenizar alguns problemas mais gritantes. E a sociedade começa, então, buscar respostas para os que se encontravam sem vínculos e sem qualquer proteção.

Dessa forma o Estado social surge com o compromisso de mediar interesses de mercado e as reivindicações do trabalho. Surge, principalmente no cenário europeu do pósSegunda Guerra, e se fortalece no contexto da guerra fria, o Estado de Bem Estar Social.

A essência do Estado de Bem Estar Social reside na proteção oferecida pelo governo na forma de padrões mínimos de renda, alimentação, saúde, habitação e educação, assegurada a todos os cidadãos como um direito. Em outras palavras, o Estado de Bem Estar Social representa a institucionalização dos direitos sociais nos marcos do capitalismo, em sua era de ouro.

Ao mesmo tempo que a economia capitalista cresceu, intensificaram-se a rigidez dos compromissos de Estado com programas de assistência que aumentavam para manter a legitimidade num momento em que a rigidez da produção restringia gastos públicos e essa rigidez que tanto tempo sustentou o capitalismo acabou decretando o fim do Estado de Bem Estar Social e do padrão de acumulação fordista.

No final do século $X X$ a economia novamente se reestrutura, na verdade se flexibiliza, e com ela toda a política social. Surge o padrão de acumulação flexível, baseado na flexibilização dos processos de trabalho, mercado, políticas e direitos sociais, com ele surge também o neoliberalismo, que propõe manter um Estado forte para controlar gastos sociais e ao mesmo tempo fraco para intervir no mercado. Assim reduziu-se a seguridade social, e o Estado de Bem Estar Social parece estar chegando ao fim, portanto, é necessária uma nova alternativa, é preciso criar novas estratégias sociais para combater 
as conseqüências do modo de produção capitalista, ainda mais aprofundadas pela globalização e pelo neoliberalismo.

No atual contexto, a questão social se agrava, permanentemente a burguesia precisa fazer algo para manter o capitalismo, porém sem deixar que o Estado "re-assuma" totalmente o poder político e econômico. Qual seria então a solução para manutenção dessa etapa do capitalismo? Uma componente da resposta parece ser a "responsabilidade social empresarial". O direito social coletivo passa a ser novamente substituído por obrigações morais, conduzido pelos setores privados da sociedade.

Em síntese, ao longo da história, a questão social vem sofrendo um processo de metamorfose, que passou de uma concepção fragmentária, implícita, desarticulada e privada para uma ação articulada, intencional e conduzida pelo Estado, e, de certa forma retornando, às ações explícitas porém fragmentadas e conduzidas diretamente pelos setores privados, particularmente, o empresariado. A solidariedade, então, é assumida novamente pelo discurso assistencial de entidades privadas com uma nova roupagem de voluntariado. Dentro dessa atual preocupação de promover uma "economia solidária", isto é, de criar vínculos entre questões econômicas e coesão social, surgem novas entidades assistenciais chamadas entidades do terceiro setor que desenvolvem uma espécie contemporânea de assistencialismo através de programas voluntários.

Podemos perceber que o passado inspira o futuro, e que velhas respostas metamorfoseadas estão sendo usadas para responder às novas questões.

Assim, o centro da questão social de hoje e de ontem permanece, no fundo, o mesmo: Qual é a responsabilidade da sociedade (cidadãos, Estado, empresas, etc.) e quais meios que ela lançará mão para resolver esses problemas que estão postos e ameaçam a coesão e o desenvolvimento econômico, político e social?

\section{A responsabilidade social no Brasil e suas origens}

Até chegar ao estágio de responsabilidade social, que presenciamos a partir dos anos 1990, a assistência no Brasil também passou por várias metamorfoses, desde 1930, quando o país começa a enfrentar problemas de nação industrializada. Até a Revolução de 30, no Brasil, a pobreza e as suas conseqüências era considerada "caso de polícia" por parte do Estado. Os problemas sociais eram mascarados sob a forma de fatos esporádicos, uma disfunção dos indivíduos, e somente a partir a década de 1930, ou seja, com a Era Vargas, que o Estado vai reconhecer a questão social como uma questão política a ser resolvida sob sua direção.

Durante a Era Vargas, o Estado institucionaliza direitos sociais, criam-se ministérios para coordenar ações nos campos do trabalho, saúde e da educação, além de inúmeras leis trabalhistas. A questão social deixa de ser "caso de polícia" e passa a ser objeto de política, sendo usada como mecanismo para atenuar tensões sociais, sem é claro, atentar 
contra a propriedade privada ou tocar nas relações de produção.

Dessa forma antigas ações isoladas e fragmentadas de assistência cedem lugar a uma política, que continua assistencialista, na qual podemos citar a criação, em 1942, da Legião Brasileira de Assistência (LBA), também institui-se a elevação de padrões mínimos como a educação dos trabalhadores, seja com a criação naquele mesmo ano do Serviço Nacional de Aprendizagem da Indústria (SENAI), seguidos, em 1946, pela criação do Serviço Social da Indústria (SESI) e do Serviço Social do Comércio (SESC), seja com o conjunto das chamadas Leis Orgânicas do Ensino.

Assim, o serviço de assistência social no Brasil afirma-se estreitamente ligado ao setor público, onde a noção de assistido e beneficiário do Estado permanece através de diversos programas de desenvolvimento comunitário e formação de mão-de-obra para atender aos interesses capitalistas.

Durante o Regime Militar (1964-1985) o assistencialismo se intensifica como meio de intervenção governamental. No processo de abertura da ditadura, pós-1975, podemos destacar como principais medidas sociais o processo de unificação das instituições previdenciárias através da criação do Instituto Nacional de Previdência Social (INPS).

Com a re-estabilização da democracia, a Constituição de 1988 rompe com o caráter assistencialista, com o objetivo de alcançar uma cidadania plena através do reconhecimento dos direitos sociais, colocando a assistência social como parte integrante da Seguridade Social.

Contudo, a letra da Constituição de 1988 não foi suficiente para sanar a questão social e o novo padrão de acumulação surge com novas exigências, assim o papel social do Estado passa a ser reconstruído sob a nova ótica da "flexibilidade", iniciada a partir do Governo Collor (1990-1992).

O Estado vai se afastando de suas obrigações sociais e passando apenas a organizar programas de caráter emergencial, tirando a responsabilidade social do governo e repassando para outras instâncias, privatizando, terceirizando assim a implementação das políticas sociais. Um exemplo dessa nova política é o fechamento da LBA e a criação, com posterior modificação, da Comunidade Solidária no Governo Fernando Henrique Cardoso (1995-2003).

Assim, responsabilidade social emerge na década de 1990 como a nova estratégia da assistência em uma sociedade cada vez mais regida por múltiplas instâncias de poder, ou seja, uma "rede de casamatas" da sociedade civil, da qual as entidades empresariais assumem um caráter relevante.

Com a globalização e a entrada de novos competidores estrangeiros no Brasil, se intensificaram as formas, e as práticas de gestão e de relacionamento da empresa. $A$ sistematização de formas e práticas empresarias foi materializada através de uma opção 
estratégica do empresariado pela educação, dentro e fora das empresas. Mas a educação stricto sensu não é o único alvo empresarial na corrida pelo selo de qualidade social. Com crescentes investimentos, os empresários estão vinculando a sua ação social à várias áreas além da educacional e assistenciais, áreas de cultura, meio ambiente, esportes, lazer. Nesse contexto, cada vez mais criam-se fundações, institutos e departamentos dentro das próprias empresas para desenvolverem de forma sistematizada essas ações.

Campanhas como o Movimento Nacional de Ação da Cidadania Contra a Fome, a Miséria e pela Vida, fazem parte dessa estratégia contemporânea de responsabilidade social no Brasil. Vinculada a uma atitude filantrópica e assistencialista, pessoas se mobilizam para fazer doações e promover arrecadações de gêneros de primeira necessidade, mas não para modificar a situação política e econômica instalada que causa a má distribuição e conseqüentemente a fome, dentre outros malefícios sociais .

Campanhas como a supracitada contribuíram para despertar o interesse do empresariado em desenvolver ações sociais dentro de empresas, só que com uma pequena, mas fundamental diferença, de forma mais sistemática, lançando mão de sofisticadas estratégias pedagógicas para o fortalecimento de imagem pública.

Segundo o dicionário de Ciências Sociais (Biroui, 1976, p.361) Responsabilidade Social pode ser definida como: "Responsabilidade daquele que é chamado a responder pelos seus atos face à sociedade ou à opinião pública (...) na medida em que tais atos assumem dimensão ou conseqüência sociais". Um compromisso que a empresa deve ter com a sociedade.

A responsabilidade social pode ser definida como o novo ethos empresarial que pretende dar uma direção cultural e política à sociedade. E que se procura incluir na totalidade social, através de permanente ação educativa, (re)produzindo certos valores e padrões sociais.

A responsabilidade social empresarial é, portanto, uma forma, uma filosofia de gestão das empresas, uma estratégia disseminada através de uma nova cultura empresarial, proclamadamente baseada em pilares como ética, cidadania e solidariedade. Dessa forma ser "socialmente responsável" para as empresas, hoje, vem se tornando um dos pilares de sustentação dos negócios, proclamadamente tão importante quanto a qualidade, a tecnologia e a capacidade de inovação.

Na verdade essa cultura é um sintoma da ultra exploração capitalista, que chegou a um ponto tão avançado de pauperização, exclusão e exploração da grande maioria. É preciso, então, planejar novas formas de atuação social, de preferência que amenize a exploração sem prejudicar o desenvolvimento do capitalismo, isto é, sem afetar as bases da reprodução ampliada do capital. Nessa atual fase de desenvolvimento capitalista, o "social" re-adquire importância, mas sob o controle direto do capital. 
Em síntese, o processo de responsabilidade social trabalha principalmente com valores culturais. Um fio invisível que amarra acontecimentos políticos, econômicos e sociais em beneficio do empresariado. A responsabilidade social, então, marca uma nova cultura social, evidenciada no Brasil pelo surgimento de várias entidades e institutos que proclamadamente utilizam essa estratégia com o intuito do desenvolvimento da cidadania da justiça social e da ética nos meios empresariais como o Instituto Ethos de Responsabilidade Social Empresarial, nosso objeto de análise.

\section{O Pensamento Pedagógico do Instituto Ethos}

O Instituto Ethos de Empresas e Responsabilidade Social apropria-se do vocábulo grego ethos que se refere aos costumes, ao caráter, à moral, ao "espírito de uma época", o tom determinante do sentimento de um povo ou de uma comunidade. Em outras palavras, de ethos deriva ética, que significa "modo de ser" ou "caráter", enquanto forma de vida também adquirida ou conquistada pelo homem. Nesse sentido, ethos não corresponde a uma disposição natural, mas que é adquirido ou conquistado por hábito. Segundo o Instituto Ethos (2000), ética é "Ciência do dever humano em seu sentido mais amplo, conjunto de regras de conduta do convívio entre pessoas".

Já a expressão "ethos empresarial" foi cunhada, ou pelo menos disseminada, pela Comissão Econômica para a América Latina da ONU (CEPAL), para qualificar as expectativas geradas em torno da concepção de modernidade. Para Rummert (2000, p.13) o ethos empresarial é a base do pensamento hegemônico e contém em si características do projeto identificatório burguês no plano societário e educacional.

O Instituto Ethos de Empresas e Responsabilidade Social é uma das principais organizações do país a sistematizar o tema e a promover a prática da responsabilidade social empresarial. Foi fundado em julho de 1998, em São Paulo, pelos empresários Guilherme Peirão Leal e Oded Grajew.

O Instituto Ethos foi um desdobramento da ação de empresários organizados na entidade Pensamento Nacional de Bases Empresariais (PNBE). Desse movimento de discussões sobre questões de engajamento empresarial, ao qual, podemos incluir também a sistematização de campanhas sociais no inicio da década de 1990, o Ethos é fruto.

Internacionalmente, o Instituto Ethos está ligado ao Business for Social Responsability (BSR), a principal entidade mundial no setor de responsabilidade social, uma associação que reúne 1.400 empresas americanas que assumem ter compromissos sociais. A maioria é de multinacionais do porte da Ford, Johnson \& Johnson e AT\&T. Juntas, as associadas da BSR somam um faturamento anual acima de 1 trilhão de dólares.

O BSR, fundado em 1992, é sediado nos Estados Unidos, conduz projetos e programas em nível global que buscam incentivar empresas a alcançarem sucesso em seus negócios através de práticas socialmente responsáveis. 
O Ethos se define como entidade sem fins lucrativos, de caráter não governamental, que tem como missão mobilizar, sensibilizar e ajudar as empresas a adotar uma gestão socialmente responsável num permanente processo de avaliação e aperfeiçoamento.

O Ethos, portanto, é uma associação de empresas que buscam o sucesso econômico sustentável a longo prazo procurando adotar um comportamento socialmente responsável.

Para se associarem, as empresas são previamente avaliadas. Uma empresa que não esteja sintonizada com práticas socialmente responsáveis e que não pretenda rever sua gestão em busca dessa sintonia não é aceita nos quadro do Ethos.

A pergunta em questão é: Por que se associar ao Ethos? Segundo Oded Grajew não é nenhuma credencial para as empresas estarem associadas ao Ethos, porém empresas que avançam em responsabilidade social possuem vantagem competitiva porque ganham espaço e mercado. Essa vantagem competitiva acelera o processo de adesão que passa a acontecer espontaneamente por parte das empresas que percebem a responsabilidade social como um diferencial no mercado competitivo.

As empresas têm acesso a essas informações através de outras empresas, da mídia, das publicações e das conferências do Ethos. As empresas interessadas, então, procuram a assessoria do Ethos, sendo posteriormente visitadas por ela, recebem manuais e debatem sobre a incorporação de valores supostamente éticos e socialmente responsáveis, montam suas próprias metas e ações e preenchem uma ficha de adesão com todos seus dados e com uma sugestão de contribuição financeira ao Instituto.

As empresas associadas ao Instituto Ethos contribuem com uma taxa mensal que varia de acordo com o faturamento anual da empresa, porém nada impede que as empresas contribuam com valores mais altos do que os indicados na tabela.

Segundo o Ethos, os valores de contribuição são definidos de forma que não onere as empresas e contribua para a sustentabilidade das atividades do Instituto Ethos.

Veja a seguir a tabela de valores sugeridos para contribuições, que relaciona o faturamento da empresa ao valor de contribuição mais indicado.

\begin{tabular}{|c||c}
\hline \multicolumn{2}{|c}{ Contribuição mensal } \\
\hline \hline Faturamento anual (R\$ milhões) & Contr \\
\hline \hline Até 1,2 & \\
\hline De 1,2 a 5 & \\
\hline De 5 a 10 & \\
\hline De 10 a 50 & \\
\hline \hline De 50 a 100 & \\
\hline \hline
\end{tabular}




\begin{tabular}{||c||c} 
De 100 a 200 & \\
\hline \hline De 200 a 400 & \\
\hline \hline De 400 a 700 & \\
\hline \hline De 700 a 1.000 & \\
\hline \hline Acima de 1.000 & \\
\hline \hline
\end{tabular}

A quantia sugerida é, de fato, pequena. Por exemplo, se o faturamento da empresa associada for de dez milhões de reais a sugestão de contribuição parte de 150 reais. Não é essa renda que o Ethos está buscando, pois é uma entidade empresarial dirigida por empresários que possuem suas próprias empresas e querem que elas sejam lucrativas e mantenham-se no mercado. Portanto o "lucro" que o Ethos busca é constituído por bens imateriais que conseqüentemente irão refletir em bens materiais.

Com efeito, o alcance do Ethos é muito grande. Com um acelerado movimento de engajamento, em sete anos, já conta com a participação de mais de 1006 empresas associadas, entre elas IBM, Pão de Açúcar, Natura, entre outras, onde o faturamento dessas empresas gera bilhões de reais, o que equivale a mais $30 \%$ do Produto Interno Bruto Brasileiro (PIB).

O Instituto Ethos divulga o seu pensamento pedagógico, educando empresas, empregados e cidadãos a produzirem e consumirem e viverem sob o lema da responsabilidade social que inclui a ética e a cidadania.

A responsabilidade social, na visão do Ethos, traduz-se na prática pedagógica de levar as empresas de qualquer tamanho e/ou setor a compreender e incorporar um comportamento empresarial socialmente responsável em sua gestão assumindo suas responsabilidades através de critérios éticos para o retorno a longo prazo sobre seus investimentos.

Para alcançar esse objetivo as empresas precisam ter coerência ética nas suas ações e na relação com seus diversos públicos. Assim, as empresas adquiririam o respeito das pessoas e comunidades que são impactadas por suas atividades e seriam gratificadas com o reconhecimentos e a preferência de seus públicos internos e externos.

Para isso, o Ethos sugere estratégias que devem ser assumidas pelas empresas associadas com o objetivo de atuar em parceria com as comunidades na construção do suposto bem estar comum.

Para cumprir o seu papel, o Instituto Ethos assume o papel de ponte entre os associados e dissemina a prática de responsabilidade social por meio de troca de experiências através de conferências, debates e encontros com empresas e através de publicações e informações especificadas em manuais e ferramentas de gestão, instrumentos de disseminação, avaliação e planejamento que oferecem uma linha de programas educacionais sobre cidadania empresarial, ética, indicadores sociais, ambientais, culturais 
e de direitos humanos que auxiliam as empresas a incorporar às suas atividades passo a passo o conceito da responsabilidade social buscando promover o aprendizado coletivo divulgando o que se faz no mundo nessa área empresarial. O objetivo dessa sistematização é permitir medir o grau de responsabilidade social comparando ações entre as empresas, ou seja, padronizando essas ações.

Os materiais que apresentam diretrizes e iniciativas para implementação e manutenção da responsabilidade social são distribuídos não apenas às empresas associadas, mas aos fornecedores dessas empresas, buscando assim atingir e influenciar o maior número possível de empresas, visando com isso intervir junto à opinião pública e conseqüentemente aos órgãos governamentais.

Na prática a análise da implementação da responsabilidade social por parte das empresas se traduz numa tábua de valores onde para cada empresa existe um processo distinto, porém interligado e bem definido.

A base do processo de implantação depende do perfil de cada empresa que deve integrar a responsabilidade social ao conjunto de suas atividades. A análise é feita sobre o perfil de cada empresa e do local onde elas estão inseridas. A empresa precisa ter conhecimento das necessidades da comunidade ao seu redor e da sociedade como um todo para trabalhar no sentido de eliminar ou amenizar suas carências, combinando seu foco de ação com o de seus públicos internos e externos, criando assim parcerias para maximizar sua ação social.

Para isso a empresa precisa levantar bandeiras com as quais a sociedade se identifica. As necessidades então, são detectadas dentro de cada empresa e cada comunidade é a partir desse diagnóstico auxiliado pelo Ethos que cada empresa vai implementar suas ações socialmente responsáveis.

Depois do diagnóstico identificando as necessidades da empresa e comunidades, deve-se iniciar o planejamento das atividades estabelecendo as principais metas, onde deve ser elaborado um projeto que atinja a comunidade interna e externa, este projeto posteriormente será apresentado aos clientes e fornecedores para captar recursos.

Antes de executar suas ações a empresa deve gerar exemplaridade, ou seja, cuidar de seus funcionários, não poluir, não fraudar, proteger o meio ambiente, não aceitar matéria prima obtida do trabalho de menores ou que tenha devastado a natureza, ou poluído o ambiente, organizar projetos ecológicos, de reciclagem, ou de uso eficaz de energia. Minimizando assim impactos negativos.

Para que a responsabilidade social de efetivo retorno à empresa são necessárias ações mais contundentes, como desenvolver projetos sociais interligados com instituições comunitárias, escolas, postos de saúde, centros de esporte e outros, envolvendo-se em todos acontecimentos da comunidade, apoiando eventos locais, apoiando o comércio 
local, emprestando suas instalações em benefício de programas comunitários, para encontros, aulas e eventos de grupos e organizações sem fins lucrativos.

A empresa deve fazer doações de seus equipamentos, produtos e serviços, inclusive dos funcionários, comprometendo-se a fazer contribuições, designando uma porcentagem de suas vendas para organizações comunitárias, além de encorajar a contribuição por parte de seus funcionários, clientes e fornecedores. Ações com estas não representam grande ônus financeiros, mas são fundamentais para a imagem da empresa, indispensáveis para saber se a ação está atingindo seus objetivos.

A própria empresa deve criar um ambiente de troca de informação e experiências, promover encontros, saber o que está sendo feito na mesma área, levando suas ações ao conhecimento da sociedade e dos órgãos públicos através do marketing social, a fim de atrair novos colaboradores e parceiros, arejar as idéias e descobrir novos métodos, daí a importância das publicações, sites, banco de dados, manuais e ferramentas de gestão divulgadas e mantidas pelo Ethos.

O Ethos, portanto é um centro produtor de metodologias que supostamente diminuiriam diferenças e formariam sentimento de identidade social a partir dos ideais burgueses.

Para avaliar os investimentos sociais das empresas o Ethos observa o retorno na imagem, na marca, no mercado (facilitação da entrada em novos mercados), nas vendas (captação de novos clientes) e nos tributos (dedução do imposto de renda e incentivos fiscais).

Em outras palavras, para o Ethos, os investimentos para o desenvolvimento econômico de uma empresa deve incorporar inovações organizacionais, pedagógicas, culturais.

Em síntese, o propósito do Ethos é trabalhar com empresas ajudando-as a conciliarem duas práticas, dois conceitos contraditórios: a competitividade e a cidadania.

Com efeito, para o Instituto Ethos, as empresas devem buscar ser lucrativas implementando práticas que respeitem as pessoas, as comunidades e o meio ambiente.

Sabemos, contudo, que não há como conciliar essas duas lógicas que são distintas e antagônicas, ou seja, é impossível promover a igualdade buscando lucro e participando da competição capitalista. Na verdade, a prioridade da "missão" do Ethos é disseminar um comportamento empresarial que implementa políticas e práticas que demonstram aos seus acionistas a relevância de um comportamento socialmente responsável para o retorno, a longo prazo, de seus investimentos. Ou seja, a "responsabilidade social" é apenas uma senha conveniente para o aumento, ou manutenção, da lucratividade, isto é, da exploração da classe trabalhadora.

A responsabilidade social empresarial torna-se, assim um novo recurso pedagógico do capital, perdendo seu caráter social para se tornar uma marca individual, uma espécie de selo de qualidade, a ser utilizado como moeda de troca, em meio a (des) organização 
social capitalista.

Apesar da percepção dos problemas sociais já estar institucionalizada não existe um conceito responsabilidade social facilmente aceito (disseminado no senso comum) sobre responsabilidade social. Ou seja, o Ethos veicula e disputa na sociedade principalmente entre o empresariado, não só, o seu conceito de responsabilidade social, mas conceitos políticos, éticos, culturais, educativos.

Para os ideais de uma classe se tornarem hegemônicos na sociedade é preciso um trabalho de convencimento, uma ação pedagógica. Nesse sentido, a primeira ação pedagógica do Ethos é agregar em torno de si diferentes segmentos da classe burguesa , sistematizando e disputando a direção moral do conjunto da classe, e, em seguida, disputar a hegemonia no conjunto da sociedade. Nesse processo pedagógico, o Instituto Ethos combina estratégias racionais e afetivas..

Assim, para fixar suas idéias, a classe dominante, através de instituições como o Ethos, produz e reproduz suas próprias representações da vida social. Para manter a sua hegemonia e preservar o status quo esconde as condições sociais de exploração e de dominação, fazendo com que pareçam justas e insuperáveis. Essa é, portanto, a função a ideológica e pedagógica desenvolvida pelo Instituto Ethos: ocultar diferenças de classes e criar sentimento e identidade social sob a direção da burguesia "socialmente responsável".

\section{A responsabilidade social em perspectiva}

$\mathrm{Na}$ atual etapa de economia flexível, o capitalismo destruiu direitos sociais, para reconstruí-los de forma mais flexível, através da responsabilidade social. Há uma metamorfose da lógica que permeia as ações sociais por parte do empresariado decorrente da nova etapa do modo de produção capitalista.

A pergunta que se faz necessária é: as mudança propostas pelo empresariado são suficientes para transformar a sociedade, livrando-a das mazelas sociais? É possível atenuar significativamente as mazelas sociais sem acabar com o próprio sistema capitalista?. Para responder a essa questão precisamos observar algumas contradições imediatas da responsabilidade social empresarial em ação.

As empresas que mantém ações na área social também recebem incentivos fiscais do governo, como abatimentos dos impostos e outras vantagens, também agregam valor "social" a sua marca e com isso aumentam a sua lucratividade.

Além disso, empresa que utiliza recursos para projetos sociais prejudica o bem estar público, pois não repassando recursos (impostos) para o governo reduz o estoque geral de recursos que seria utilizado na ampliação e melhorias de escolas, hospitais, seguridade social, entre outros bens e serviços públicos. Em outras palavras, a empresa socialmente responsável aplica em ações privadas recursos que deveriam ser de domínio e aplicação públicos. Recursos esses que, em geral, acabam beneficiando apenas uma comunidade 
específica, geralmente, aquela na qual a empresa está inserida, em outras palavras a responsabilidade social está atuando sobre aquilo que muda pouco.

Em outras palavras, o recurso público acaba sendo distribuído através de ações particularizadas que só agravam as desigualdades, uma vez que a ação do empresariado é muito pequena para atuar sobre mudanças estruturais Contraditoriamente a política do Ethos afirma que as mudanças sociais no Brasil, ou em qualquer lugar do mundo, não virão a não ser através de políticas públicas (por isso as pressões do empresariado sobre as decisões nas políticas educacionais).

O empresariado se beneficia com o atual processo de produção, onde a reestruturação produtiva implica em mudanças no espaço de trabalho além dos esvaziamentos no âmbito do Estado, promovido também com a participação do empresariado. O empresariado, então é beneficiado com o desmonte de seguridades, com os programas de demissão voluntária, pelo próprio esvaziamento da legislação trabalhista, quer dizer, o empresariado esta ganhando por este lado e dando através de ações de responsabilidade social por outro lado, ou seja, dando muito menos ao conjunto da sociedade. Porém no discurso oficial, as empresas socialmente responsáveis são apresentadas como salvadoras dos lugares e reconhecidas por trazer emprego, modernidade e ações sociais.

Dentro desse contexto, o Instituto Ethos logrou, no plano discursivo, articular desenvolvimento econômico e medidas sociais, o resultado foi a grande adesão por parte do empresariado pela responsabilidade social. A inovação do Ethos foi interpretar as expectativas do mercado e redirecionar a postura das empresas lançando mão de inúmeras estratégias através do pensamento pedagógico

O Ethos segue as mesmas diretrizes de outras fundações e institutos que também desenvolvem esse trabalho, mas com uma diferenciação fundamental, patenteia e vende um selo que sempre existiu no mercado, sob os mais variados nomes, das mais variadas formas, a assistência, e a usa em seu benefício.

O Ethos assumiu uma contradição dentro de seu pensamento pedagógico empresarial, tentando conciliar dois lados de processos opostos, capitalismo e responsabilidade social, uma competição solidária, para atingir esse objetivo o Ethos precisa lançar mão de um pensamento relativamente sofisticado. É esse pensamento pedagógico que passa a constituir o novo recurso competitivo do capital, que através de instrumentos como a ética, se coloca em meio à contradição de como mediar interesses privados e responsabilidade social.

A burguesia através do discurso da responsabilidade social vende sonhos de uma sociedade mais justa e solidária, e assim vão moldando comportamentos e estabelecendo prioridades através de estratégias pedagógicas. Assim é a responsabilidade social que através de um sistema determinado de idéias exprime e oculta o significado real de suas relações. 
É fundamental percebermos a importância da contradição vivenciada e difundida pelo Ethos em seu pensamento pedagógico empresarial que tenta conciliar negócios, competitividade e ética. Analisar essas contradições e suas potencialidades é fundamental para a criação de novos processos contra-hegemônicos.

\section{REFERÊNCIAS BIBLIOGRÁFICAS}

ADCE. [ on line] Disponível em: <http:/www.adce.org.br>. Acesso em: fev/2002

ASHLEY, Patrícia Almeida (coord). Ética e Responsabilidade Social nos negócios. São Paulo: Saraiva, 2002. BSR [ on line] Disponível em: <http: //www.portal-rp.com.br/bibliotecavirtual/responsabilidadesocial. > Acesso em abril/2005.

CARDOSO, Alexandre Jorge Gaia; ASHLEY, Patrícia Almeida. A responsabilidade social nos negócios: um conceito em construção. In: ASHLEY, Patrícia Almeida (coord). Ética e Responsabilidade Social nos negócios. São Paulo: Saraiva, 2002.

CASTEL, Robert. As metamorfoses da questão social: uma crônica do salário - tradução de Iraci D. Poleti Petrópolis, Rio de Janeiro: Vozes, 1998.

CIVES[on line] Disponível em: <http:// www.cives.com.br>. Acesso em: fev/2002.

COSTA, Carolina. Escola de cidadania. Revista Educação. São Paulo. dez/2000.

EMPRESAS ASSOCIADAS AO ETHOS [ on line] Disponível em: < www.portaldovoluntário.org.br>, abril/2005.

ETHOS. [on line] Disponível em: <http://www.ethos.org.br>. Acesso em: dez/2001

FIDES, Fundação Instituto de Desenvolvimento Empresarial e social. Ética na Atividade empresarial: Pesquisa, 1999. Documento FIDES 2, São Paulo, FIDES, 2000.

[on line] Disponível em: <http://www.fides.com.br>. Acesso em: fev/2002.

FRIGOTTO, Gaudêncio (org) Educação e crise do trabalho: Perspectivas de final de século. Petrópolis: Vozes, 1998.

GIFE. . [on line] Disponível em: <http://www.gife.com.br>. Acesso em: fev/2002.

HARVEY, David. Condição pós-moderna: Uma pesquisa sobre as origens da mudança cultural. São Paulo: Loyola, 1992. (5ª ed.).

HOBSBAWM, Eric. Era dos extremos: o breve século XX: 1914-1991. São Paulo: Companhia das Letras, 1995.

IANNI, Octavio. Estado e planejamento econômico no Brasil. (5ª ed.). Rio de Janeiro: Civilização Brasileira, 1991.

INSTITUTO ETHOS. Responsabilidade social das empresas: percepção e tendências dos consumidores brasileiros. São Paulo. 2000. [on line] Disponível em: <http:// www.ethos.org.br>. Acesso em dez/2001

Transparências Ethos. Plano de Ação do Instituto Ethos. São Paulo, jun.1999.

Indicadores Ethos de responsabilidade Social Empresarial. Junho/2000. [on line]

Disponível em: <http//www.ethos.org.br>. Acesso em: dez/2001.

abril/2005.

Tabela de contribuições. [on line] Disponível em:<http// www.ethos.org.br>. Acesso em

Empresas associadas.[on line] Disponível em: <http//

www.ethos.org.br/pri/openempresasassociadas>. Acesso em abril/2005.

LIBÂNEO, José Carlos. Pedagogia e pedagogos para quê? São Paulo: Cortez, 1998.

LIDIA, Maria. Debate sobre responsabilidade social. Presença dos debatedores: Waldemar de Oliveira Neto, 
superintendente do Instituto Ethos de empresas e responsabilidade social, Evelin loschpe, presidente da Fundação loschpe e Conselheira do Grupo de Institutos, Fundações e Empresas (GIFE) e Antonio Carlos Martinelli, consultor de cidadania do GIFE e criador do Instituto Seara na rádio CBN, em maio de 2001. [on line] Disponível em: <http://globonoar.globo.com/cbn/cbn_voluntária.htm> Acesso em: agosto/2001.

MENDONÇA, Sonia Regina de. Estado e economia no Brasil: opções de desenvolvimento. (2 ${ }^{\mathrm{a}}$ ed.). Rio de Janeiro: Graal, 1988.

PNBE . [on line] Disponível em: <http://www.pnbe.org.br>. Acesso em: fev/2002.

RODRIGUES, José. O moderno príncipe industrial: o pensamento pedagógico da Confederação Nacional da Indústria. Campinas: Autores Associados, 1998.

RUMMERT, Sonia Maria. Educação e identidade dos trabalhadores: as concepções do capital e do trabalho. São Paulo: Xamã, Niterói, Intertexto, 2000.

SAVIANI, Dermeval. A nova lei da educação: Trajetória, limites e perspectivas. Autores Associados: Campinas, 1997.

VENTURA, Elvira Curvinel Ferreira. O Banco Central do Brasil. In: ASHLEY, Patrícia Almeida (coord). Ética e Responsabilidade Social nos negócios. São Paulo: Saraiva, 2002.

. Responsabilidade social das organizações: estudo de caso no Banco Central do Brasil. Rio de Janeiro, 1999. Dissertação de Mestrado apresentada à Escola Brasileira de Administração Pública, Fundação Getúlio Vargas.

[] Licenciada em Pedagogia (UFF - 2002)

volta

file://C:|Documents and Settings\AdministradorlMeus documentos\Minhas Webs\NED.. 28/8/2008 